\title{
Management of Infected Radicular Cyst by Marsupialization
}

\author{
Prateek Agarwal, Sunil Sharma, Mridula Trehan, Abhishek Vashistha
}

\begin{abstract}
Cystic lesions are frequent in the oral cavity. They are defined as a pathologic cavity with or without fluid or semifluid material. Radicular cysts are the most common odontogenic cystic lesions of inflammatory origin affecting the jaws. They are most commonly found at the apices of the involved teeth. This case report presents the successful surgical management of large infected radicular cyst involving entire body region of right side of mandible. We illustrate the possibility of healing of cystic periapical lesions with conservation of vital structures.
\end{abstract}

Keywords: Odontogenic cyst, Periapical pathology, Marsupialization.

How to cite this article: Agarwal $P$, Sharma $S$, Trehan $M$, Vashistha A. Management of Infected Radicular Cyst by Marsupialization. World J Dent 2013;4(3):214-216.

Source of support: Nil

Conflict of interest: None declared

\section{INTRODUCTION}

Radicular cysts are the most common (52-68\%) cystic lesions affecting the jaws. They are most commonly found at the apices of the involved teeth, however they may also be found on the lateral aspects of the roots in relation to lateral accessory root canals. ${ }^{1}$ Their prevalence is highest among patients in their third decade of life, among men than women. The natural history begins with a nonvital tooth which remains in situ long enough to develop chronic periapical pathosis. ${ }^{2}$

Most cases of periapical lesion do not present any symptom unless an exacerbated inflammatory response is present out of the infection. In the X-ray it appears as regular periapical transparencies circumscribed by a well-defined radiopaque line with loss of the hard lamina at least in the periapical region and possible root resorption. To confirm the diagnosis it is necessary an incisional or excisional biopsy, which should be preceded by a puncture and aspiration. $^{3}$

Cystic lesions can receive endodontic (conservative) or surgical (enucleation, marsupialization and decompression) treatments.

This case report presents the successful surgical management of large infected radicular cyst.

\section{CASE REPORT}

A 58-year-old male patient was referred to our department with the chief complaint of painful swelling of 1 week duration in right side of lower jaw along with pus discharge.
Patient gives a history of recurrent swelling and pus discharge since 6 months which got relieved on taking medications. Patient revealed the history of extraction of mandibular right second premolar (45) and mandibular right first molar (46) 4 months back.

On extraoral examination, diffuse swelling was present in the mandibular right posterior region extending anteroposteriorly from body region up to angle region and superoinferiorly from external oblique ridge to the lower border of mandible (Fig. 1). There were no sign and symptoms of paresthesia seen. Intraoral examination revealed a unilateral, diffuse swelling with obliteration of the vestibule in association with mandibular right canine (43) to mandibular right second molar (47) region (Fig. 2). On palpation the

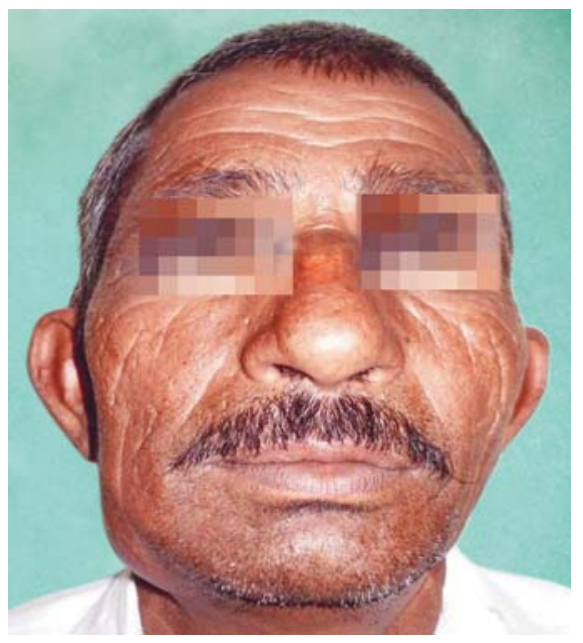

Fig. 1: Initial preoperative photograph with buccal swelling

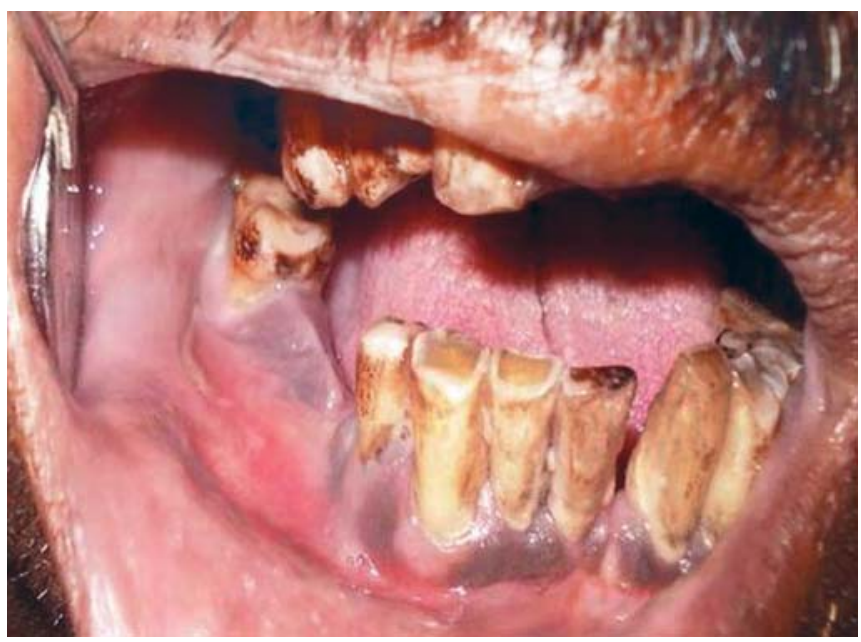

Fig. 2: Clinical view with obliteration of vestibule in relation to 43 and 47 
lesion was approximately $3 \times 3 \mathrm{~cm}$, soft to firm in consistency.

Orthopantomogram (OPG) X-ray revealed a welldefined radiolucency in relation to the roots of 43 and 47 and approaching till lower border of mandible (Fig. 3). Occlusal radiograph showed a dark, dense oval shaped radiolucent lesion approximately $5 \times 3 \mathrm{~cm}$ in dimension present on right body region (Fig. 4).

A fine needle aspiration of the swelling showed a discharge containing pus and blood. Based on history and clinical examination a provisional diagnosis of infected radicular cyst was made and cyst marsupialization was planned under local anesthesia. Complete blood count and other routine investigation were under normal limit. Histopathology of aspirated fluid showed RBC's and inflammatory cells indicating inflammatory exudates thereby favoring our diagnosis as infected radicular cyst.

Incision was made over the alveolar crest region of edentulous area so that flap lies on the sound bone and there is good accessibility. Bone is removed to expose the underlying cystic lining. The underlying cyst lining is gently eased away from the cavity and specimen was sent for histopathological examination. Extraction of the offending tooth was also performed. All the vital structures were preserved. Bleeding points were arrested with the help of pressure pack and gelfoam. Cystic cavity was irrigated with normal saline and povidone-iodine solution. The cavity was then packed with half inch width ribbon gauze impregnated with iodoform glycerin paste(Figs 5 and 6 ). Histopathological examination of marsupialized tissue confirmed the diagnosis as infected radicular cyst with cystic lumen lined by stratified squamous epithelium showing an arcading pattern.

Postoperative instructions were given to the patient and patient was kept under antibiotics and analgesics. The dressing was changed after every 15 days.

OPG were repeated at 1, 3, 6 and 12 months which revealed progressively decrease radiolucent area of cystic space and evidence of new bone formation was seen (Fig. 7). The extraoral swelling caused by expansion of the buccal cortical plate also disappeared completely (Fig. 8).

\section{DISCUSSION}

Radicular cysts are thought to arise from epithelial cell rests of Malassez in the periodontal ligament, and they are believed to proliferate as a result of periapical inflammation caused by infection of the root canal system. ${ }^{4}$

Apical periodontal cysts are inflamatory lesions leading to bone resorption and can reach great dimensions and become symptomatic when infected or with great size due to nerve compression. Histopathologically it shows cystic lumen, lined with a thin epithelial lining supported by a fibrocellular

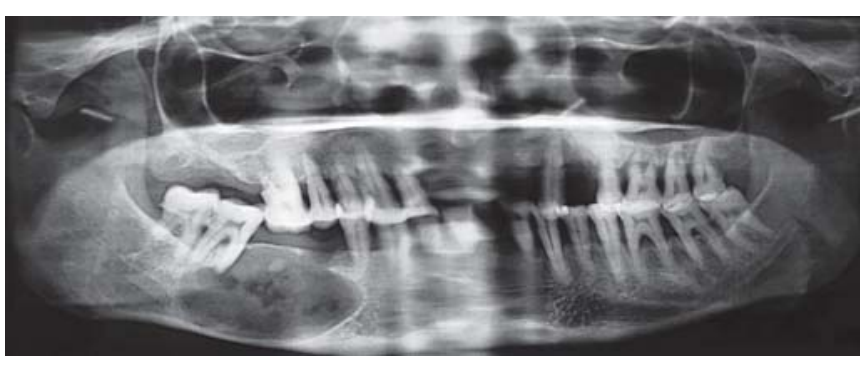

Fig. 3: Preoperative orthopantomogram showing a large well-defined radiolucent lesion

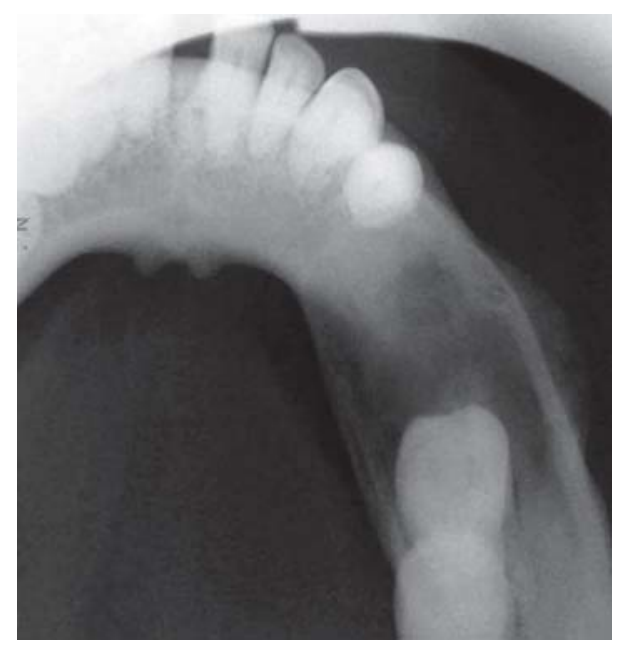

Fig. 4: Occlusal radiograph showing expansion of buccal and lingual cortical plates

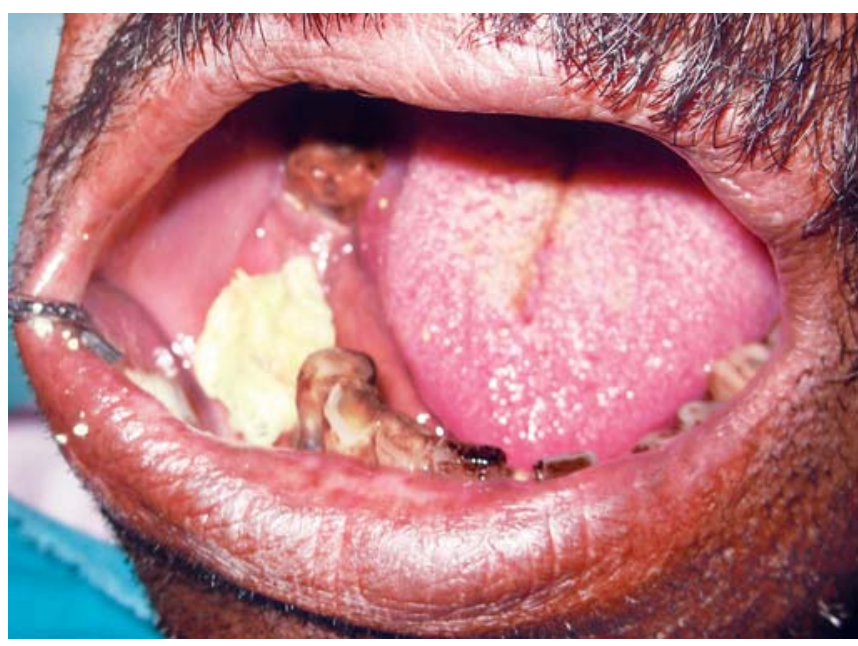

Fig. 5: Clinical view of cavity packed with iodoform dressing

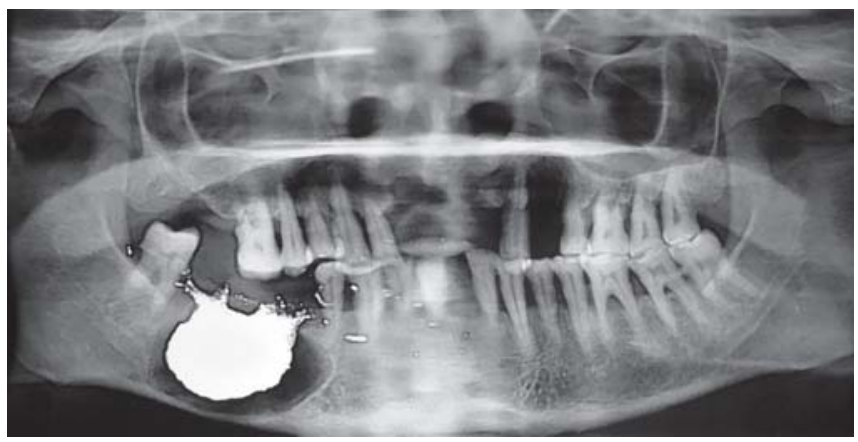

Fig. 6: A panoramic radiography showing iodoform dressing completely filling the defect 


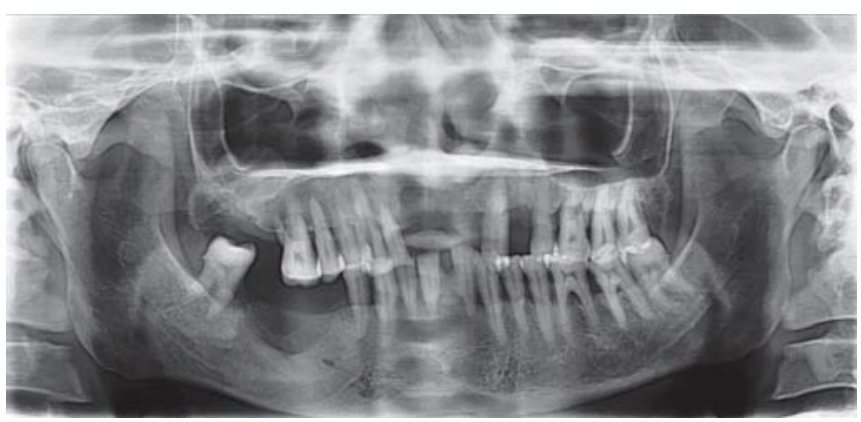

Fig. 7: One year follow-up orthopantomogram suggesting satisfactory bone radiopacity and neoformation

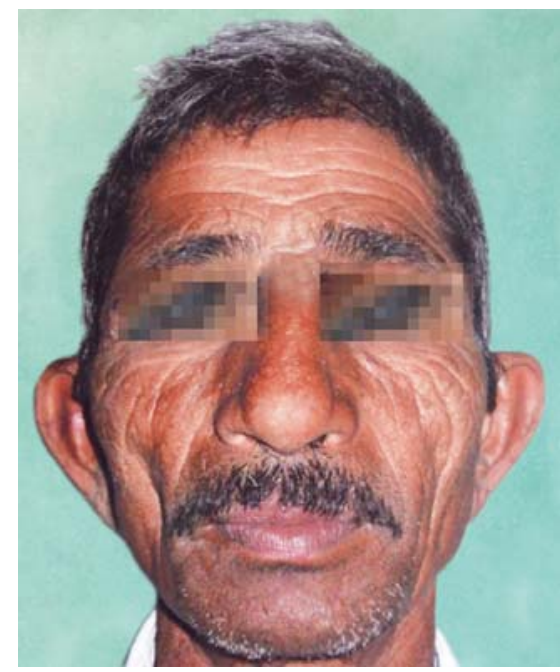

Fig. 8: One year follow-up photograph with no buccal swelling

connective tissue stroma, showing dense chronic inflammatory cell infiltrate with few cholesterol clefts. ${ }^{5}$

There are two main theories regarding the formation of the cyst cavity. The nutritional deficiency theory ${ }^{6,7}$ is based on the assumption that the central cells of the epithelial strands become removed from their source of nutrition and undergoes necrosis and liquefactive degeneration to form the cyst cavity lined by stratified epithelium. The abscess theory ${ }^{6,7}$ postulates that proliferating epithelium lines an abscess cavity formed by tissue necrosis and lysis because of the innate nature of the epithelial cells to exposed + connective tissue surfaces.

The treatment of these cysts is still under discussion and many professionals opt for a conservative treatment by means of endodontic technique. However, in large lesions the endodontic treatment alone is not efficient and it should be associated to a decompression or a marsupialization or even to enucleation. ${ }^{8,9}$

In the present case due to the patient's apprehension regarding the presence of a swelling and also the lesions size and extent along with the bone integrity of the cystic wall and its proximity to vital structures surgical procedure of marsupialization was adopted allowing new bone to fill the defect, leading to substantial reduction in the size of the cystic cavity. It shows lower morbidity compared to enucleation in terms of preservation of important anatomical structures, such as the adjacent teeth and the inferior alveolar nerve.

Endoscopically assisted enucleation is an innovative alternative method that can be as conservative as marsupialization, allowing preservation of important surrounding structures, with the greater advantage of onestep treatment, reduced healing period and very low morbidity. ${ }^{10}$

\section{REFERENCES}

1. Nair PNR. Nonmicrobial etiology: periapical cysts sustain posttreatment apical periodontitis. Endodontic Topics 2003;6: 96-113.

2. Ghezta N. Surgical enucleation of large radicular cyst-case report. J Dento Fac Sci 2012;1(2):29-32.

3. Ribeiro PD, Gonçalves ES, Neto ES. Surgical approaches of extensive periapical cyst. Considerations about surgical technique. Salusvita Bauru 2004;23:317-328.

4. Daanie TL, Juan JSE, Angela RC. Treatment of large maxillary cyst with marsupialization, decompression, surgical endodontic therapy and enucleation. J Can Dent Assoc 2011;77:b87.

5. Gibson GM. Case report: a large radicular cyst involving the entire maxillary sinus. General Dentistry 2001;50:80-81.

6. Suhail L, Ajaz AS, Suhail MJ. Radicular cyst. JK Science 2009;11(4):187-189.

7. George TJH. Apical cyst theory: a missing link. Dental Hypothesis 2010;1(2):76-84.

8. Danin J. Outcomes of periradicular surgery in cases with apical pathosis and untreated canals. Oral Surg Oral Med Oral Path Oral Radiol. Endodontic 1999;87:227-232.

9. Rees JS. Conservative management of a large maxillary cyst. Int Endod J 1997;30:64-67.

10. Heleia NZ, Ene M. Endoscopically assisted enucleation of a large mandibular periapical cyst. Stomatologija, Baltic Dent and Maxillofacial J 2011;13:128-131.

\section{ABOUT THE AUTHORS}

\section{Prateek Agarwal (Corresponding Author)}

Postgraduate Student, Department of Oral and Maxillofacial Surgery Mahatma Gandhi Dental College and Hospital, Jaipur, Rajasthan, India Phone: 01412591063, e-mail: drprateek86@gmail.com

\section{Sunil Sharma}

Dean, Principal and Head, Department of Oral and Maxillofacial Surgery, Mahatma Gandhi Dental College and Hospital, Jaipur Rajasthan, India

\section{Mridula Trehan}

Director, PG Studies and Head, Department of Orthodontics and Dentofacial Orthopedics, Mahatma Gandhi Dental College and Hospital, Jaipur, Rajasthan, India

\section{Abhishek Vashistha}

Professor, Department of Oral and Maxillofacial Surgery, Mahatma Gandhi Dental College and Hospital, Jaipur, Rajasthan, India 


\section{World Journal of Dentistry}

\section{Copyright Ownership and Legal Rights Statement}

\section{CONDITIONS FOR SUBMISSION}

You warrant that the work/contribution is your original research material and has not been published before and should not be under consideration of publication elsewhere except for previous publication in form of an abstract or as part of published literature (review or thesis) as may be included with the written permission of the copyright owners. You further warrant that the work/contribution (i) is not subject to any prior claim, encumbrance or agreement, (ii) will include appropriate warnings of harmful instructions, formulas and procedures, and (iii) will not contain any material that violates any copyright, personal proprietary or other right. This exclusive grant of rights under this Agreement means that you may not delegate, assign, sub-contract or license the work/contribution in whole or in part to third parties without the prior written consent of the Publisher.

If your work/contribution contains extracts or material from other copyright works, you will obtain at your own expense before a paper can be considered for publication along with written permission, which shall be forwarded to the Publisher on delivery of the work/contribution from each copyright holder to use and reprint such material in all versions, forms and media now or hereafter known, including all existing and future copyright and any renewals and extensions thereof anywhere in the world. Furthermore, you will identify such material (if any) in the work/ contribution and provide full and appropriate acknowledgement of its source. If such permissions are not obtained in a timely manner, you will provide substitute material, revise the work/contribution accordingly and obtain the requisite substitute permissions, if necessary. If relevant, you will obtain medical patient releases from patients if information about them or illustrations of them are used in the work/contribution.

\section{COPYRIGHT TRANSFER}

Once the corresponding author has signed the Copyright Transfer form, Jaypee Brothers would accept no change in authorship or in the order of the authors listed in the work/contribution. Also by signing the concerned form, the author reassigns the rights of copublishing, or translation, including the digital rights, if considered necessary in future to the publisher. In the advent of occurrence any dispute, the matter would be resolved within the jurisdiction of New Delhi court.

\section{LEGAL OBLIGATIONS}

While all care has been taken to provide accurate and correct information in accordance with the date of publication, neither the authors, editors nor publisher takes any legal responsibility for any unintentional omission or error. The publisher makes no expressed or implied warranty with respect to the information contained herein. The published material cannot be photocopied for the following purposes: general distribution, promotion, new works or resale. If this is required, specific written permission requires to be obtained from the publisher. Exclusive rights to reproduce and distribute the articles in this journal have been protected by copyright. This also covers the rights to reproduce or distribute the article as well as the translation rights. No material published in this journal can be reproduced in digital format or stored in form of electronic databases, video disks, etc without the prior permission from the publisher.

\section{COPYRIGHT TRANSFER FORM}

I have read the above mentioned details related to copyright of the work/contribution submitted and I , the author of

certify that I willingly assign the copyright of my work/contribution

to the publisher M/S Jaypee Brothers Medical Publishers $(P)$ Ltd., who will have the exclusive right of producing (in print or digital format) the complete work or any portion of it.

I hereby certify that the work which I am submitting to the publisher is my own and does not contain any matter which in anyway is infringement of the copyright law.

Name:

Date signed:

\section{FINANCIAL DISCLOSURE}

This is to certify that I , the author of

do not have any commercial association or financial interest in the publication of this work/contribution.

Name:

Date signed: 


\section{CONFLICT OF INTEREST}

This is to certify that I

do not have any commercial association or financial interest in the publication of this work/contribution.

Name:

Date signed: 